\title{
Rigid-Body Analysis of a Beveled Shape Structure in Regular Waves Using the Weakly Compressible Smoothed Particle Hydrodynamics (WCSPH) Method
}

\author{
Siti Ayishah Thaminah Hikmatullah Sahib ${ }^{1} \cdot$ Muhammad Zahir Ramli ${ }^{2} \cdot$ Muhammad Afiq Azman ${ }^{1}$. \\ Muhammad Mazmirul Abd Rahman ${ }^{1}$. Mohd Fuad Miskon ${ }^{2}$. Effi Helmy Ariffin ${ }^{3}$. Muhammad Hafeez Jeofry ${ }^{3}$. \\ Kamaruzzaman Yunus ${ }^{1}$
}

Received: 01 February 2021 / Accepted: 22 September 2021 / Published online: 13 December 2021

(c) The Author(s) 2021

\begin{abstract}
In many cases of wave structure interactions, three-dimensional models are used to demonstrate real-life complex environments in large domain scales. In the seakeeping context, predicting the motion responses in the interaction of a long body resembling a ship structure with regular waves is crucial and can be challenging. In this work, regular waves interacting with a rigid floating structure were simulated using the open-source code based on the weakly compressible smoothed particle hydrodynamics (WCSPH) method, and optimal parameters were suggested for different wave environments. Vertical displacements were computed, and their response amplitude operators (RAOs) were found to be in good agreement with experimental, numerical, and analytical results. Discrepancies of numerical and experimental RAOs tended to increase at low wave frequencies, particularly at amidships and near the bow. In addition, the instantaneous wave contours of the surrounding model were examined to reveal the effects of localized waves along the structure and wave dissipation. The results indicated that the motion response from the WCSPH responds well at the highest frequency range $(\omega>5.235 \mathrm{rad} / \mathrm{s})$.
\end{abstract}

Keywords DualSPHysics $\cdot$ Response amplitude operators $\cdot$ Seakeeping $\cdot$ Wave structure interaction $\cdot$ Weakly compressible

\section{Introduction}

Article Highlights

- In real-life complex environment, predicting the motion responses of a structure with regular waves is crucial.

- Open-source code based on weakly compressible smoothed particle hydrodynamics (WCSPH) method is used.

- Response amplitude operators (RAOs) are presented and compared with experimental and other numerical models.

- Efficient approach in WCSPH is studied to be applied in 3D motion response

Muhammad Zahir Ramli

mzbr@iium.edu.my

1 Department of Marine Science, Kulliyyah of Science, International Islamic University Malaysia (IIUM), 25200 Kuantan, Malaysia

2 Institute of Oceanography \& Maritime Studies (INOCEM), Kulliyyah of Science, International Islamic University Malaysia (IIUM), 25200 Kuantan, Malaysia

3 Faculty of Science and Marine Environment, Universiti Malaysia Terengganu, 21200 Kuala Nerus, Malaysia
Most studies on seakeeping have focused on developing theoretical and numerical models for investigating the complexity of fluid exerting hydrodynamic forces on the deformation of a structural component. This is because experiments are extremely costly and time-consuming, especially on the evaluation of individual ship designs. Numerical simulations coupled with enhanced computational power have thus become crucial for validating the theoretical predictions of hydrodynamics while providing useful insights for interpreting experimental results. Traditionally, linear and nonlinear strip theories (Kroukovsky and Jacobs, 1957) are widely employed in the assessment of potential hazards and risk factors that might harm a ship advancing in waves with an arbitrary forward speed and in the overall structural design in shipbuilding (Jensen et al., 2004).

In most linear cases, especially in low and moderately regular waves, linear methods adequately predict the vertical ship motion and wave-induced loads (Faltinsen et al., 1991), in which the problems of the boundary condition are 
generally solved through correction with the forward speed. This condition is commonly seen in the approach of the linear three-dimensional (3D) panel methods of Green's function (Chapchap, 2015; Sun et al., 2018). Nevertheless, panel methods show limitations and drawbacks if they are used for analyzing the intricate geometrical estimation of the free surface, mitigation of extreme boundary-layer separation, and solving the free-surface Green's theorem that often profoundly depends on multiplex equations (Cartwright et al., 2004). Likewise, ordinary linear strip theories, linear 3D methods, and potential flow are unsuitable for modeling large wave conditions where the ship motion would create breaking water on the surface. Thus, the fluid force must be nonlinearly treated (Lee et al., 2010).

For large wave conditions, methods coupling linear and nonlinear techniques have been used to resolve the nonlinearity in fluid force. For example, panel methods and time-domain strip theories have incorporated this coupling approach using Rankine sources to distribute particles over the hull surface (Lin et al., 2007) or Rankine panel methods to distribute particles across the keel and free surface (Huang et al., 1998). As a result, nonlinear effects are observed to be at low Froude numbers, with many discrepancies at high wave amplitudes (Fonseca and Guedes Soares, 2002). Such a limitation has been resolved via a combination of nonlinear and undirected methods comprising the Eulerian set procedure and Lagrangian trajectories for analyzing the fluid dynamics of a body, which has been shown to yield good projections for irregular ship motions and wave loads (Greco et al., 2013).

Nonlinear strip methods are mainly employed for estimating the navigation bearing of a ship advancing in waves with large amplitude motions that give rise to nonlinearities. Frequently, fully nonlinear methods presume that the wave flow is conservative with an independent line integral, continuous, and smooth with no interruption or smashing on the free surface (Chapchap, 2015). These nonlinear methods in seakeeping are generally analyzed via RANS codes. Incorporating viscous and rotational effects into RANS codes to analyze the flow and free surface waves makes it a popular nonlinear method (Tezdogen et al., 2015; Xie et al., 2019). However, nearly all these techniques are hinged on the boundary integral approach and inadequate in resolving the effect of massive water washing along with the deck, i.e., green water effect, fragmenting waves, or water spindrift. Therefore, this study used the meshfree technique of smoothed particle hydrodynamics (SPH) to address the Navier-Stokes problems for nonlinear wave structures (Cercos-Pita et al., 2015).

In this work, the Lagrangian method of SPH was implemented due to its meshless feature. The advantage of using this method is that the competitional domain is discretized into a set of interpolation points called particles, where each particle carries individual properties that evolve over time according to governing equations. This method can be adaptable and versatile with a simple algorithm for engineering applications (Tafuni, 2016; Leonardi et al., 2019). The two methods of applying incompressibility in SPH are enforcing true incompressibility and implementing small incompressibility, also known as weakly compressible SPH (WCSPH). The WCSPH is simple in concept and easy to implement in applications (Ramli et al., 2018; Dominguez et al., 2021). The application of SPH to water waves was started by Monaghan (1994) and then was further investigated by other researchers. The use of SPH has also been extended to study seakeeping analysis (Servan-Camas et al., 2016; Kawamura et al., 2016; Ma and Oka, 2019; Cheng et al., 2020). However, the analysis using SPH is still not common due to the high number of particles needed to capture details with good resolution. The method can be computationally costly, particularly in 3D applications. Therefore, a highly optimized open-source DualSPHysics code, which is based on the WCSPH that is run on a graphics processing unit (GPU), is widely used in many practical engineering problems (Altomare et al., 2020; O'Connor and Rogers, 2021; Pringgana et al., 2021). The GPU offers a high computing power in managing huge amounts of data with a significant reduction in the computation time.

The main objective of this work is to investigate an efficient approach in predicting the response amplitude operators (RAOs) of a floating structure over different wave conditions. Vertical displacements were examined using the WCSPH by DualSPHysics, where fluid and boundary domains were transformed into discrete, smoothed particles. Wave heights along the numerical wave tank (NWT) were verified before installing the floating structure, and damping zones were introduced to suppress the effect of reflective waves on the incident waves. Numerical results generated from this study were then compared with experimental data and numerical results from other studies. Consequently, this study showed that the motion responses from the WCSPH were analogous to the theoretical, experimental, and numerical results for various wave conditions along the structure.

\section{Methodology of SPH}

\subsection{Interpolation of SPH}

In SPH, numerical evaluations involve transforming the entire fluid domain in SPH into a finite set of discretely moving elements known as particles (Monaghan, 2006). These particles possess individual mass and various other properties, such as velocity, position, and pressure, which are computed through the interpolation process of neighboring particles (Dominguez et al., 2021). At any designated position vector, the estimated integral form of a function for a particle can be represented by Eq. (1): 
$\langle f(\boldsymbol{x})\rangle=\int_{\Omega} f\left(\boldsymbol{x}^{\prime}\right) \omega\left(\boldsymbol{x}-\boldsymbol{x}^{\prime}, h\right) \mathrm{d} \boldsymbol{x}^{\prime}$

where $x^{\prime}$ is another random position vector in the domain of integration $\Omega, \omega\left(x-x^{\prime}, h\right)$ is a weighting function (Liu et al., 2014) with a smoothing length, and $h$ represents the effective width of the kernel.

If $f\left(x^{\prime}\right)$ is known only for a discrete set of $N$ points $x_{1}, x_{2}, \ldots \ldots x_{N}$, then $f\left(x^{\prime}\right)$ can be estimated to give the particle approximation as follows:

$\langle f(\boldsymbol{x})\rangle=\sum_{j=1}^{N} \frac{m_{j}}{\rho_{j}} f\left(\boldsymbol{x}_{j}\right) \omega\left(\boldsymbol{x}-\boldsymbol{x}_{j}, h\right)$

where the summation index $x$ denotes a particle and $\boldsymbol{x}_{j}$ is the position vector of particle $j$ within the support domain of $x$.

For particle $i$, Eq. (2) can also be expressed as

$\left\langle f\left(x_{i}\right)\right\rangle=\sum_{j=1}^{N} \frac{m_{j}}{\rho_{j}} f\left(x_{j}\right) \omega_{i j}$

where particle $j$ carries a mass $m_{j}$ at position $x_{j}$ and a density $\rho_{j}$ within the support domain of particle $i$, i.e., $\omega_{i j}=\omega\left(x_{i}-x_{j}, h\right)$. The derivative of a function for particle $i$ can be formulated as

$\left\langle\nabla \cdot f\left(x_{i}\right)\right\rangle=\sum_{j=1}^{N} \frac{m_{j}}{\rho_{j}} f\left(x_{j}\right) \bullet \nabla_{i} \omega_{i j}$

where the equation obeys a similar integral representation and particle estimation.

$\nabla_{i} \omega_{i j}=\frac{x_{i}-x_{j}}{r_{i j}} \frac{\partial \omega_{i j}}{\partial r_{i j}}$

where $r_{i j}$ is the distance between particles $i$ and $j$. Based on Eqs. (3) and (4), the continuity and momentum equation or particle $i$ becomes

$\frac{\mathrm{D} \rho_{i}}{\mathrm{D} t}=\rho_{i} \sum_{j=1}^{N} \frac{m_{j}}{\rho_{j}} \boldsymbol{v}_{i j} \frac{\partial \omega_{i j}}{\partial x_{i}}$

$\frac{\mathrm{D} \boldsymbol{v}_{i}}{\mathrm{D} t}=-\sum_{j=1}^{N} m_{j}\left[\frac{P_{i}}{\rho_{i}^{2}}+\frac{P_{j}}{\rho_{j}^{2}}\right] \frac{\partial \omega_{i j}}{\partial x_{i}}+F$

where the summation is over all particles $j, P$ is the pressure, $\rho$ is the density, and $F$ is the body force (gravity). All interpolations of the WCSPH in this study employed a Wendland quantic kernel (Wendland, 1995; Ramli, 2018) with a length (radius) $h=1.3 d x$, which determines the resolution, where $d x$ is the initial particle spacing. In DualSPHysics, boundary conditions are based on the dynamic boundary condition (DBC), fluid-driven objects, and modified DBC. In this work, the DBC is implemented, which treats boundary and fluid particles with the same equations. This boundary condition was tested in the work of Ramli (2018).

\subsection{Characteristics of the Structure.}

In this work, an appropriate structure was chosen according to the availability of experimental datasets used for the validation process. Given that the structure was analyzed as a rigid body for a numerical prediction (Lakshmynarayanana et al., 2015), in this study, the probing model of a flexible structure (Remy et al., 2016) was used for validating the WCSPH. Figure 1 shows the composition and setup of the segmented model used in their studies, with the structure consisting of 12 segregated caissons, each fastened to a steel rod set at $57 \mathrm{~mm}$ over the deck. The square-shaped cross section of the rod was $1 \mathrm{~cm} \times 1 \mathrm{~cm}$. The principal caisson was slightly altered to generate a beveled shape (Figure 2), while the remainder caissons comprised rectangular sections. Meanwhile, an NWT of $30 \mathrm{~m} \times 16 \mathrm{~m} \times 1 \mathrm{~m}$ was used, and Table 1 shows the properties of the structure and flexible pole. Depending on the modes of deformations, vertical, horizontal, and torsional bendings were permitted for the flexible structure model. The structure motion responses and deformations were evaluated in regular and irregular waves in head waves devoid of the forwarding speed, with tracking points placed at six different locations on the structure. Table 2 shows the six local reference positions for the structure, where $x, y$, and $z$ are estimated from the stern, centerline, and hull of the structure, respectively (Figure 2). For the evaluation in regular waves, the structure motions were
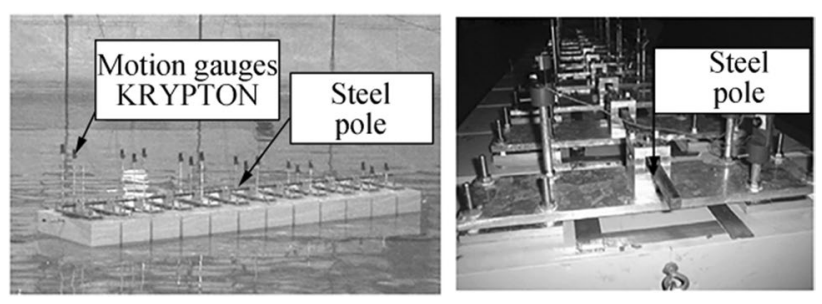

Figure 1 Experimental layout by Remy (2006)

\begin{tabular}{|c|c|c|c|c|c|}
\hline 1 & 3 & & 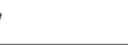 & 9 & 12 \\
\hline $\begin{array}{l}\text { Bow/ } \\
\text { fwd }\end{array}$ & \multicolumn{5}{|r|}{ Stern/Aft } \\
\hline 2.445 & $2.035 \mathrm{~m}$ & $1.625 \mathrm{~m}$ & $1.225 \mathrm{~m}$ & $0.805 \mathrm{~m}$ & $-0.19 \mathrm{~m}$ \\
\hline
\end{tabular}

Figure 2 Reference points for quantification (beveled shape of the bow) 
Table 1 Attributes of the structure

\begin{tabular}{ll}
\hline Length of structure, $L_{\mathrm{pp}}$ (caisson + clearance) $(\mathrm{m})$ & 2.445 \\
\hline Beam $(\mathrm{m})$ & 0.6 \\
Depth $(\mathrm{m})$ & 0.25 \\
Draft $(\mathrm{m})$ & 0.12 \\
$\mathrm{KG}(\mathrm{m})$ & 0.163 \\
Total mass (caissons + equipment) $(\mathrm{kg})$ & 172.5 \\
Length of each caisson $(\mathrm{m})$ & 0.19 \\
Mass of 11 caissons (except for the bow) $(\mathrm{kg})$ & 13.7 \\
Mass of 1 bow caisson $(\mathrm{kg})$ & 10 \\
Moment of inertia of the pole $\left(\mathrm{m}^{4}\right)$ & $8.33 \times 10^{-10}$ \\
Bending stiffness of the pole $\left(\mathrm{N} \cdot \mathrm{m}^{2}\right)$ & 175 \\
Young's modulus of the pole $\left(\mathrm{N} / \mathrm{m}^{2}\right)$ & $2.1 \times 10^{11}$ \\
\hline
\end{tabular}

estimated for several wave periods. Additional details of the experiment are available in Remy et al. (2006).

\subsection{Computational Setup}

Similar to the approach used for describing 2D arrangements, the boundaries of structures in the 3D domain are also discretized into particles that directly interact with the fluid domain in the NWT. Each boundary particles hold the properties of the floating structure and interact with the fluid particles at each time step. The pressure between these boundary and fluid particles was then computed to determine the updated velocity and position at each time step, which were the motion responses of the floating structure. However, because the boundary was not a symmetrical rectangular form, discretizing a boundary domain into particles could be tedious. Therefore, the fill point technique was used in this study to transform a single point into discrete boundary particles and redistribute the points throughout the domain based on the shape of the boundary (Figure 3), in which all frames were discretized without disrupting the mesh refinement of the particle (Dominguez et al., 2021).

In the numerical setups for the NWT, a 3D platform was used with the $x$-axis along with the structure and the $y$-axis and $z$-axis in the athwartships and upright directions,

Table 2 Measuring points from aft to forward of the structure respectively. Given that the symmetry boundary condition in the finite volume method was not an available option in DualSPHysics, modeling the structure and fluid domain in full dimension was essential. Thus, rendering it became computationally intensive because the dimensions of the fluid domain and side walls were dependent on the individual wavelengths $(\lambda)$. Figure 4 shows that the structure was initially placed at $1.5 \lambda$ from the wavemaker on the left side with the damping beach located at the terminus of the NWT to restrain the approaching waves. Assuming that the longest wavelength produced in this test was $5 \mathrm{~m}$, the damping beach was fixed to 1.5 times the structure length. Meanwhile, each of the side walls was fixed at $2.2 \mathrm{~m}$ from the structure's centroid for all tests, with three probes placed around the structure for tracking the advancing waves and their reflections from the side walls. The movement in the $x$-direction was also riveted, capturing only the vertical wave motion and pitching.

For the simulation of a rigid body in head waves, the particle mesh was estimated on the true size of the structure and NWT. The NWT was sufficiently large for producing waves near the floating structure while completely restraining the wave at the far end of the damping zone. Apart from the overall dimension, the choice of the appropriate particle spacing for the fluid domain and rigid boundary also depended on the total number of particles generated, computational cost required, and numerical instability. Following the preliminary convergence test of another study (Ramli, 2018), three-particle spacings with consistently well-maintained wave profiles were used in this study: $d x=0.010 \mathrm{~m}, d x=0.015 \mathrm{~m}$, and $d x=0.020 \mathrm{~m}$. Particle spacings within this range of numbers were generally deemed appropriate for the study. Given that $25 \mathrm{M}$ particles were generated from $d x=0.010 \mathrm{~m}$, i.e., larger than the utmost number that the current GPU could handle, $d x=0.020 \mathrm{~m}$ was used in all tests. The total number of particles was $4 \mathrm{M}$ particles with $3.5 \mathrm{M}$ fluid particles and $0.5 \mathrm{M}$ boundary particles. Particle spacings, i.e., $d x=0.012 \mathrm{~m}$ and $0.015 \mathrm{~m}$, were employed to examine motion responses with relatively lower frequencies in these convergence studies. Boundary particles were chosen for each wall to mimic the actual setups of the NWT. In each repetition, the movement of the piston wavemaker was controlled by a sinusoidal function. The rigid-body response of the structure in head regular waves under different test conditions was computed for five-wave periods (Table 3 ). These rigidbody responses were then compared with the findings of the 3D finite volume computational fluid dynamics (CFD) technique (Star-CCM +) proposed by Lakshmynarayanana et al. (2015) and 2D numerical (MARS) and empirical examination of Remy (2006). 
Figure 3 Transformation from the solid to particle interface

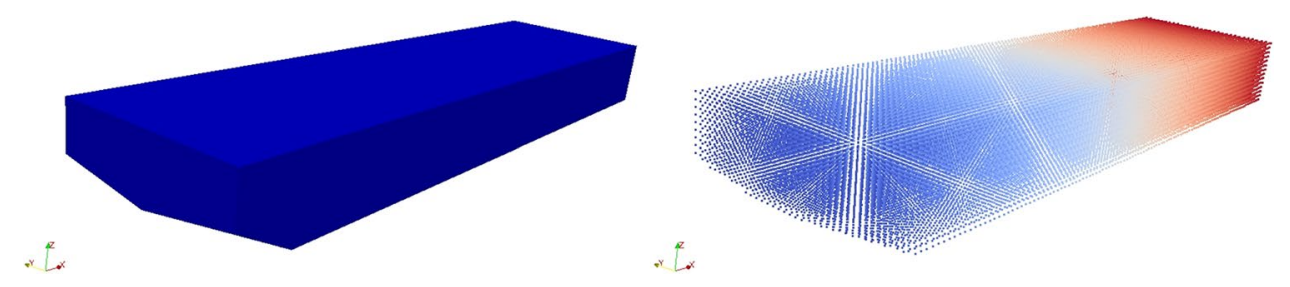

\section{Results and Discussion}

\subsection{Production of Waves via the Paddle Motion}

Prior to the installation of the structure model, the wave profiles that the piston wavemaker produced were tested for two purposes: (i) to verify the wave heights of regular waves generated at various frequencies and (ii) to establish the position of the structure with a minimum reduction in the wave height while allowing a gap between the structure and wavemaker for periodic solutions without being corrupted by reflection. A similar experiment was conducted on the 2D case for the WCSPH with a satisfactory result (Ramli, 2018). However, wave reflections from the side walls were not assessed in these tests, which could influence the wave height (Lakshmynarayanana et al., 2015). In this study, six additional probes were incorporated into the analysis. Figure 5 shows all six tracking probes. The tracking points were fixed within $1.5 \lambda$ from the wavemaker based on frequencies, and then wave heights were noted in each repetition. Experiments were performed in various conditions to optimize the results.

In Figure 5, dotted lines representing findings from the WCSPH were compared with the analytical results of the $0.10 \mathrm{~m}$ wave height. The wave profiles and analytical solution were generally congruent, except for minor discrepancies at relatively low frequencies. The time record of the wave advancement for $\omega=3.490 \mathrm{rad} / \mathrm{s}$ showed a minimum wave dissipation at each probe, with the largest reduction

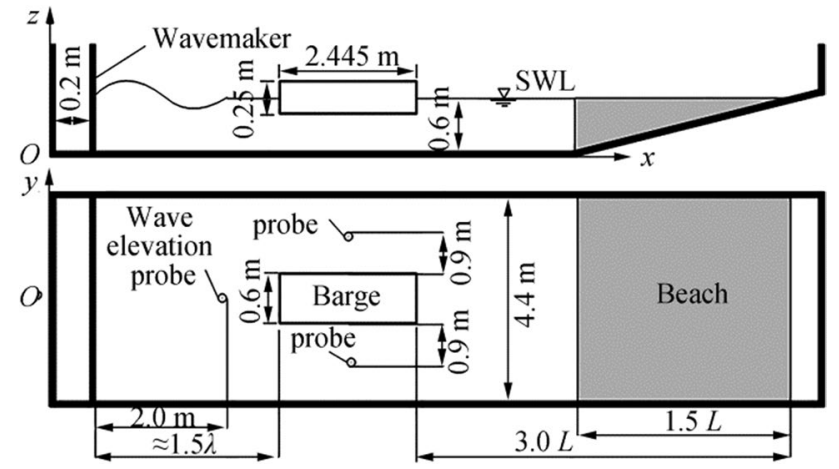

Figure 4 Top and side views of the computational structure of $12 \%$ in the wave height throughout the test (Figure 6). Figure 7 shows the wave advancement at different time steps, and the visualization could be enhanced by depicting the particles onto the surface via IsoSurface.exe in DualSPHysics (Crespo et al., 2015).

\subsection{Rigid-Body Motion Responses in Head Waves.}

Figure 8 presents the RAOs calculated from the WCSPH, in which the amplitudes from four to six wave periods were averaged to yield RAOs. The 2D linear potential flow yielded rigid-body motion responses via the strip theory, designated as MARS (Bishop and Price, 1979), and a finite element method using ABAQUS (version 6.14) denoted by STAR. In the absence of distortions, displacements comprising solely rigid-body motions of heaves and pitches were represented by MARS_Rigid and STAR_Rigid. A particle spacing $d x$ of $0.020 \mathrm{~m}$ used for all simulations was denoted by the WCSPH. Altogether, MARS_Rigid qualitatively agreed well with STAR_Rigid in responses, except for minor discrepancies around points 7 and 9 with relatively low frequencies. Supplementary hydroelastic measurements from Remy et al. (2006) were graphed to chart the relation between motion responses and deformations. The results from the experimental data reflect the behavior of a flexible structure, providing insights on how it differs in comparison with motion responses from rigid structures.

Overall, the behaviors of flexible and rigid structures differed in several ways. At comparatively high-frequency ranges of $\omega>5.235 \mathrm{rad} / \mathrm{s}$, the instantaneous wave contour around the body exerted $3 \mathrm{D}$ effects on the structure at points 1,3 , and 5 , which was indicative of overestimation by the WCSPH (Figure 9). The 3D effects were largely the results of strong but localized nonlinear wave systems, and a 2D linear model of the potential flow theory would not project it

Table 3 Selected numerical experimental setups

\begin{tabular}{llll}
\hline$T(\mathrm{~s})$ & $\omega(\mathrm{rad} / \mathrm{s})$ & $\lambda(\mathrm{m})$ & $H(\mathrm{~m})$ \\
\hline 1.8 & 3.490 & 5.058 & 0.1 \\
1.6 & 3.926 & 3.996 & 0.1 \\
1.2 & 5.235 & 2.248 & 0.1 \\
1.0 & 6.283 & 1.561 & 0.1 \\
0.9 & 6.981 & 1.264 & 0.1 \\
\hline
\end{tabular}


Figure 5 Average wave height at each tracking probe (prior to installing the barge) at various frequencies

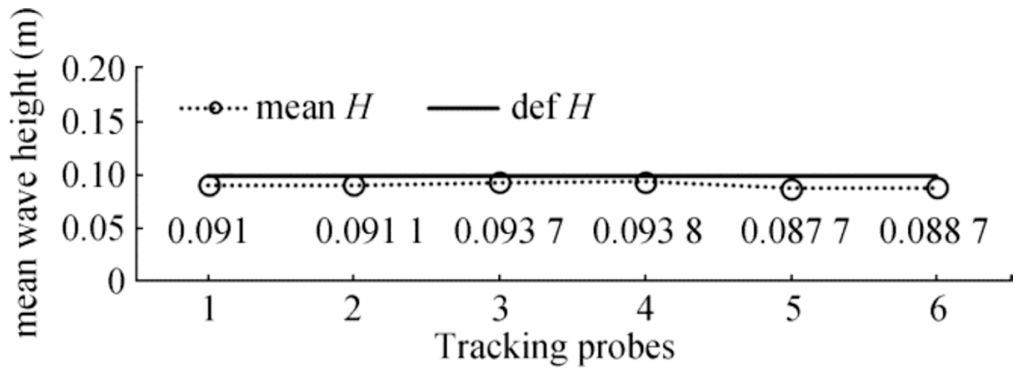

(a) $T=1.8 \mathrm{~s}, \omega=3.490 \mathrm{rad} / \mathrm{s}$

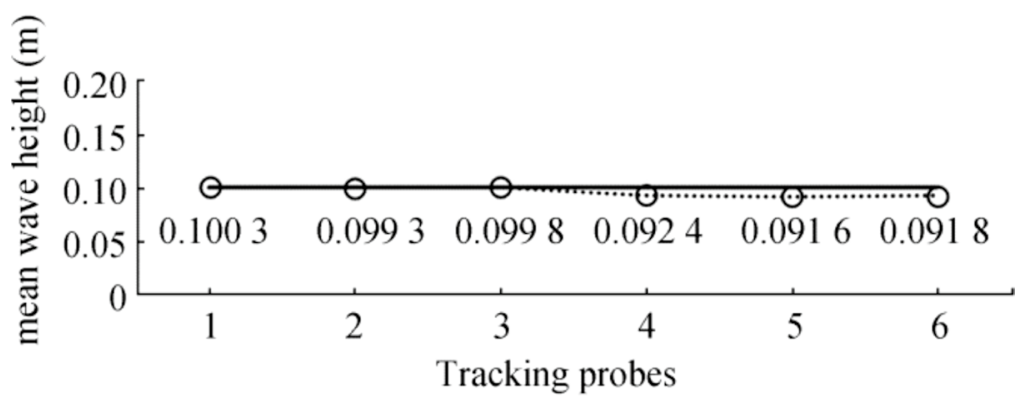

(b) $T=1.6 \mathrm{~s}, \omega=3.926 \mathrm{rad} / \mathrm{s}$

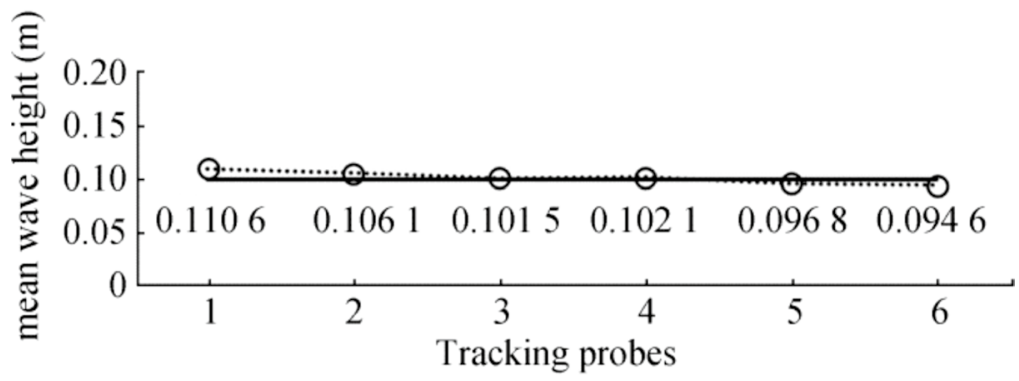

(c) $T=1.2 \mathrm{~s}, \omega=5.235 \mathrm{rad} / \mathrm{s}$

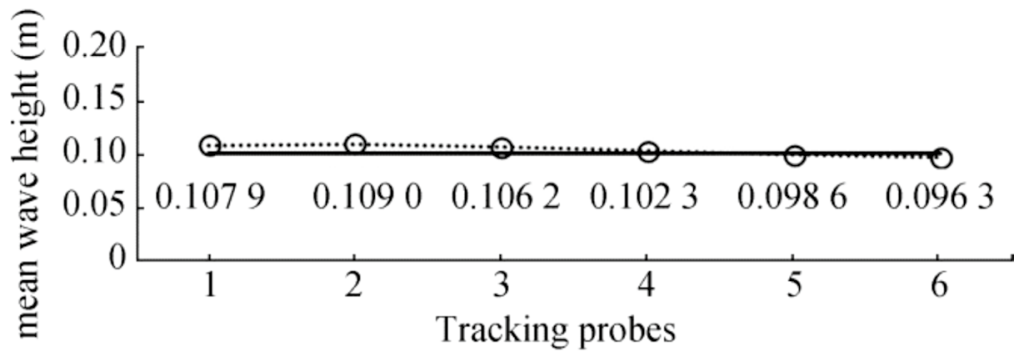

(d) $T=1.0 \mathrm{~s}, \omega=6.283 \mathrm{rad} / \mathrm{s}$

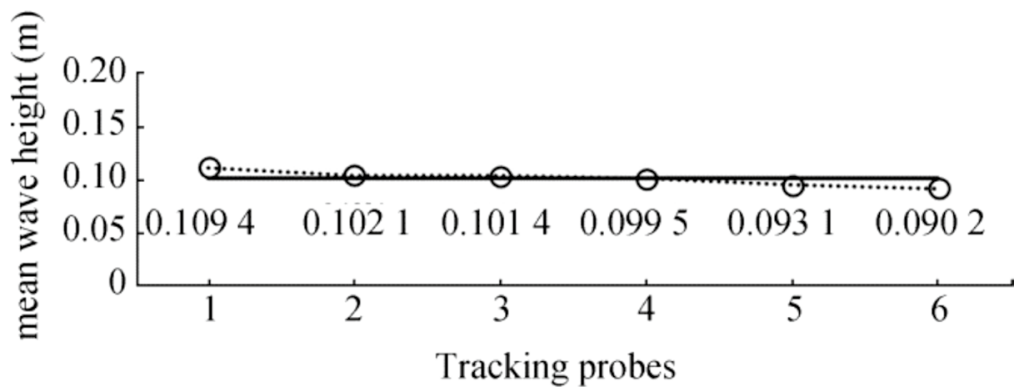

(e) $T=0.9 \mathrm{~s}, \omega=6.981 \mathrm{rad} / \mathrm{s}$ 


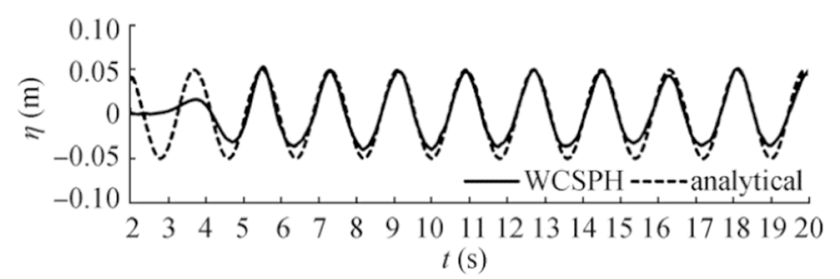

(a) Point 1

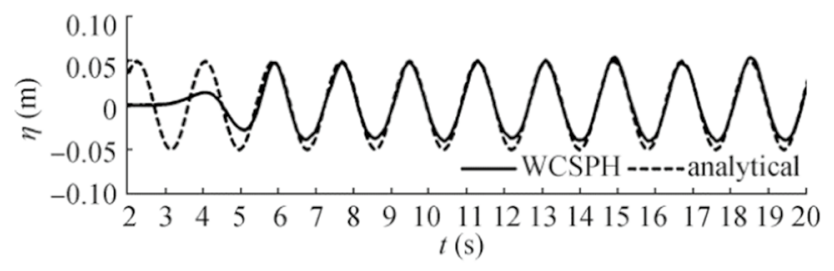

(b) Point 3

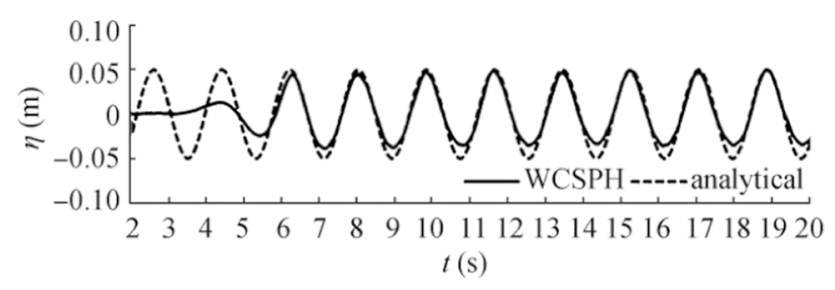

(c) Point 5

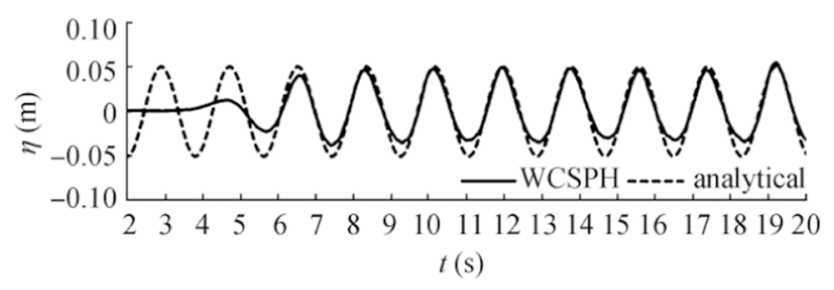

(d) Point 6

Figure 6 Time history of the wave elevation along the NWT without the structure. $T=1.8 \mathrm{~s}, \lambda=5.058 \mathrm{~m}(\cong 0.7 \lambda)$

appropriately. However, projections from the WCSPH were lower than that of STAR_Rigid, notably at $\omega=5.283 \mathrm{rad} / \mathrm{s}$ with the largest difference of less than $30 \%$. Lower WCSPH projections were probably due to the waves fragmenting on the free surface around the forward section. The repulsive character of the dynamic boundary particles could also cause fluctuations in pressure that affect the flow fields. Predictions from the WCSPH and STAR_Rigid agreed better with the experimental data at all points for the highest frequency. In this case, the impact of diffraction prevailed at the vicinity of waves approaching the bow, perturbing the free surface at the structure regardless of its flexible or rigid condition, thus yielding a minor change in the vertical motion.

When $\omega<5.235 \mathrm{rad} / \mathrm{s}$, most deviations from the potential theory were revealed. Overprediction occurred at points 1 , 3 , and 12 for the WCSPH, whereas at points 5, 7, and 9, the values underpredicted the potential theory. The rigid structure was most likely linked to the impact of a strong bow and stern waves because of the motion when moving in the pitch motion. Nevertheless, most projections were closely complemented with STAR_Rigid, except for points 7 and 9, probably because of their distant locations from the bow and stern. At positions near the bow (point 1) and stern (point 12), the flexible structure was deformed following the wave advancement, thus generating lower vertical responses than the potential theory.

For points 7 and 9, the attributes of the projection marginally varied from MARS_Rigid and STAR_Rigid, largely because these points were located at the amidships, where the fluid dynamic was primarily affected by the vertical motion of the barge. However, the added mass coefficient obtained from the WCSPH did not corroborate well with the theoretical and experimental data collected at lowfrequency ranges. This discrepancy might be attributable to the fluctuations of pressure at the interface between the fluid and structure.

A thorough assessment between RAOs at various frequencies is given in Figures 10 and 11 with colors representing the velocity of the created waves. At $\omega=3.926 \mathrm{rad} / \mathrm{s}$, with $\lambda \geq 2.245 \mathrm{~m}$ (length of the structure), the bow reflected most of the waves arriving in succession. A higher wave velocity encircling the bow suggests a strong influence of slamming due to higher vertical displacement, thereby generating an uninterrupted and strong but localized wave contour along with the structure, notably at the amidship (points 7 to 9). This nonlinear pattern was not visible in the symmetry boundary approach in
Figure 7 Wave advancements at various moments in the simulation at $\omega=6.283 \mathrm{rad} / \mathrm{s}$. Colors represent the swiftness of wave movements

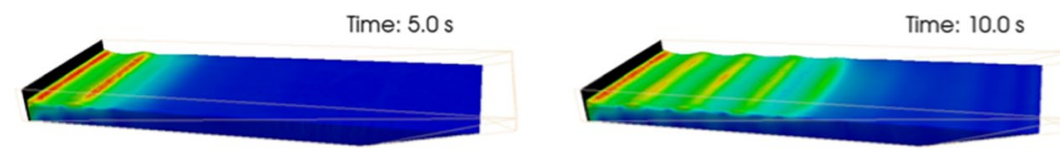

Time: $15.0 \mathrm{~s}$
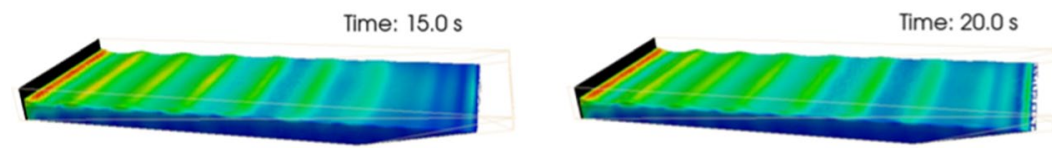


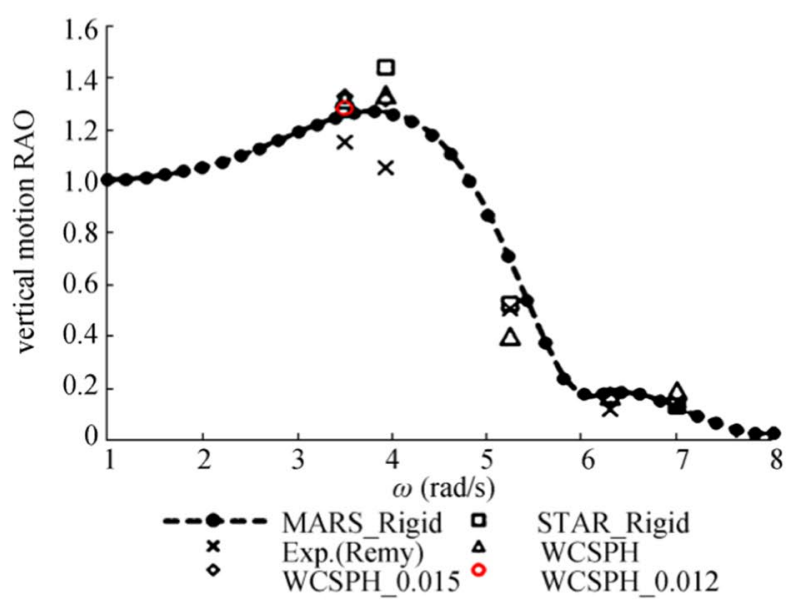

(a) Response at point 12

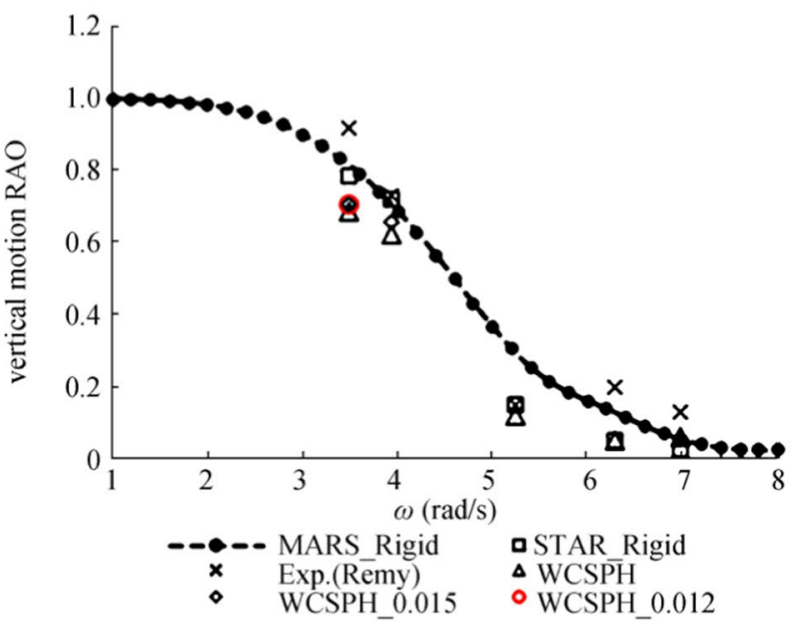

(b) Response at point 9

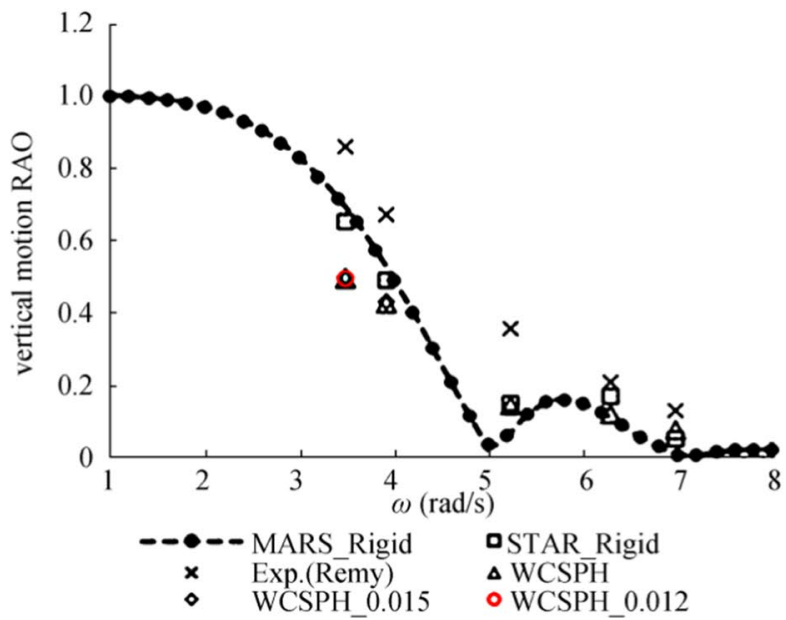

(c) Response at point 7

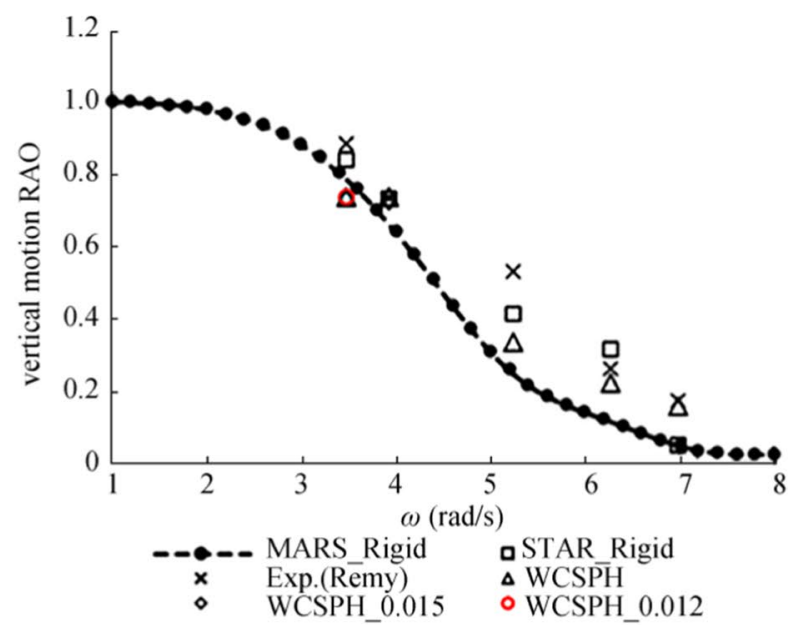

(d) Response at point 5

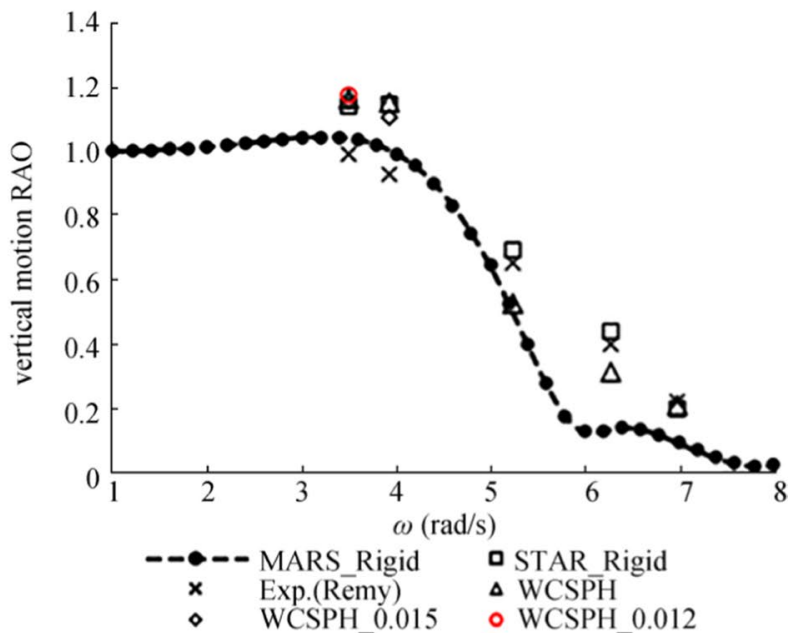

(e) Response at point 3

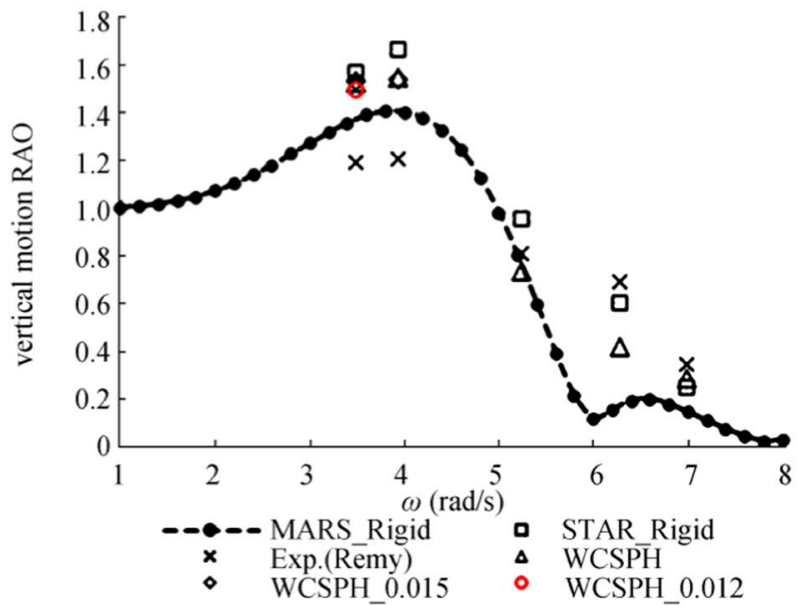

(f) Response at point 1

Figure 8 RAO values of vertical displacements along with the structure. In the analyses of the rigid and flexible bodies, point 12 was located near the stern and point 1 near the bow, as shown in Figure 2 


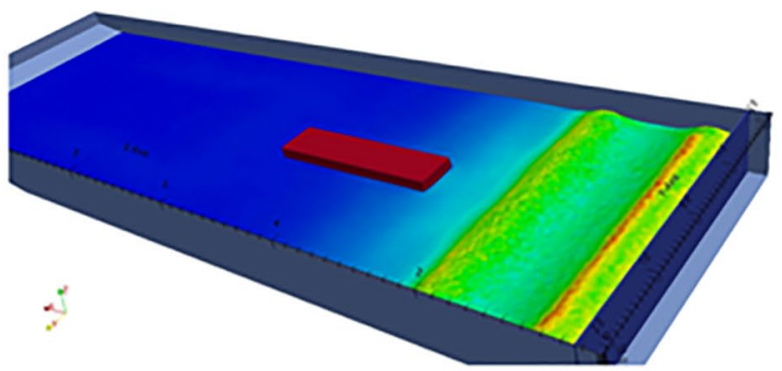

(a) $t=5.0 \mathrm{~s}$

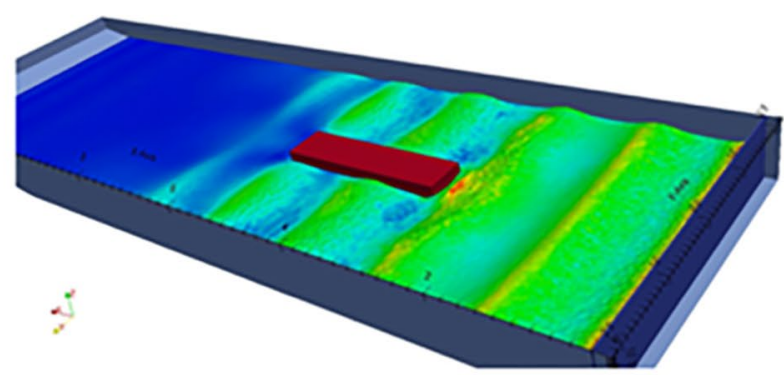

(b) $t=10.0 \mathrm{~s}$

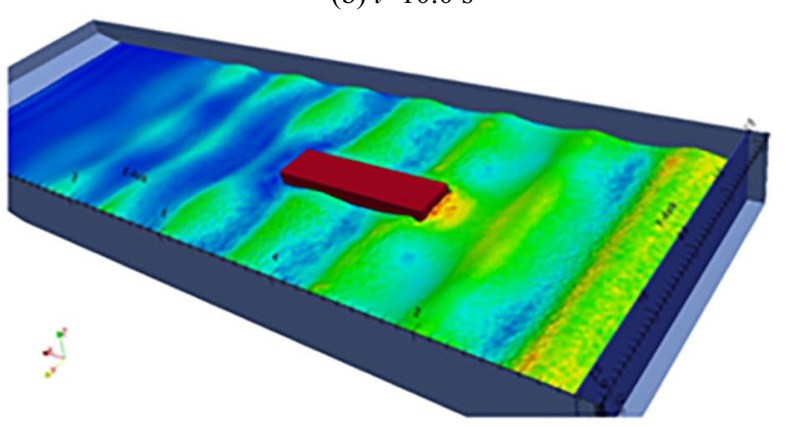

(c) $t=15.0 \mathrm{~s}$

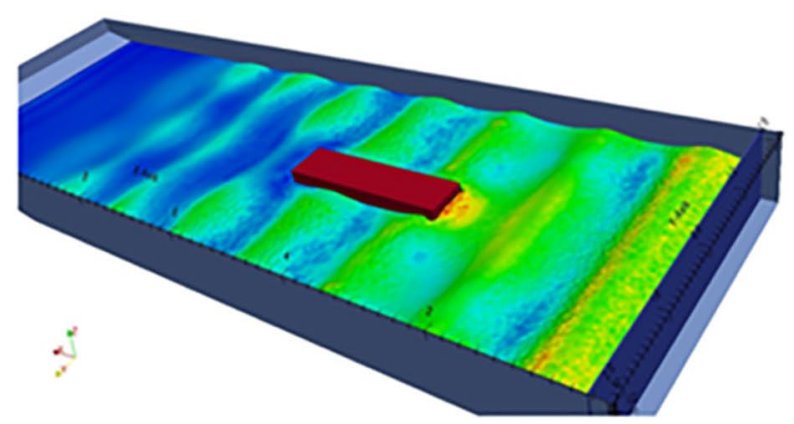

(d) $t=20.0 \mathrm{~s}$

Figure 9 Development of the wave profile hitting the floating barge for $\omega=6.981 \mathrm{rad} / \mathrm{s}$

STAR-Rigid, which could explain the discrepancy around the amidship area. Figure 11 shows a similar nonlinear pattern for high frequencies, with the slamming effect occurring at the bow, which could differentiate the 3D motion

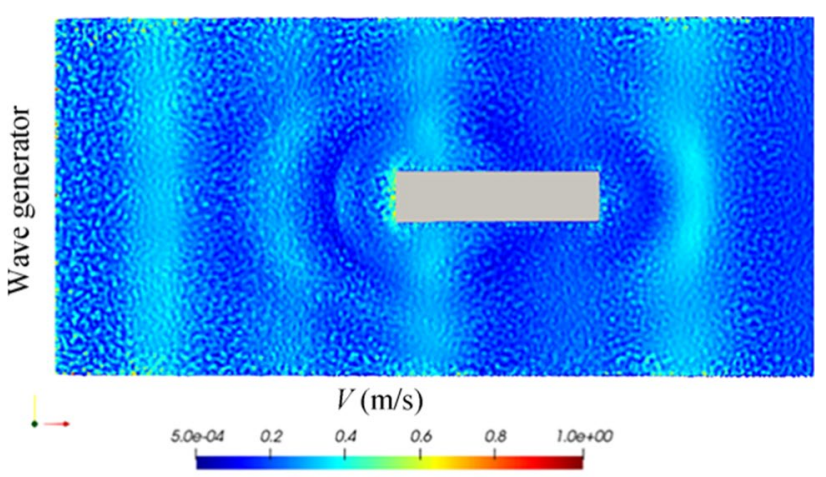

(a) $9.15 \mathrm{~s}$

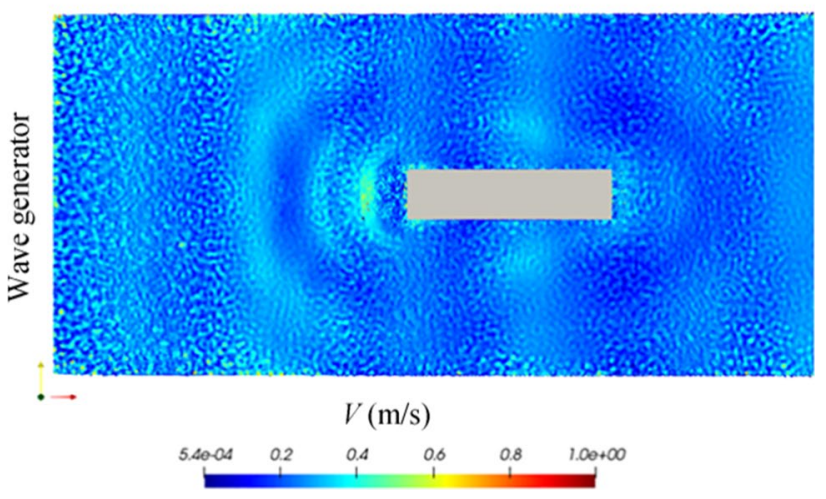

(b) $9.85 \mathrm{~s}$

Figure 10 Illustration of the instantaneous wave contour surrounding the rigid structure at $9.15 \mathrm{~s}$ and $9.85 \mathrm{~s}$ for $\omega=3.926 \mathrm{rad} / \mathrm{s}$

from its $2 \mathrm{D}$ equivalent in the simulation. A high frequency appeared to produce short waves that traveled through the structure with minimal wave dissipation. Therefore, the vertical displacement around the amidship was less perturbed and maintained similar responses, as shown in Figure 8.

To better understand the relationship of particle spacing and the accuracy and capability of the WCSPH in predicting the RAOs for low-frequency ranges, particle numbers were increased for two cases of $\omega<3.490 \mathrm{rad} / \mathrm{s}$ and $\omega<3.926 \mathrm{rad} / \mathrm{s}$. The simulations are expected to yield a better prediction as what has been observed in the case of propagating regular waves. The number of particles was carefully selected on the basis of keeping the balance between the acceptable accuracy of the simulation and a reasonable computational cost. Both cases shown in Figure 8 were denoted as WCSPH_0.012 and WCSPH_0.015 with $18 \mathrm{M}$ and $9 \mathrm{M}$ particles, respectively. However, both results did not show any significant improvements, particularly at the amidships. 


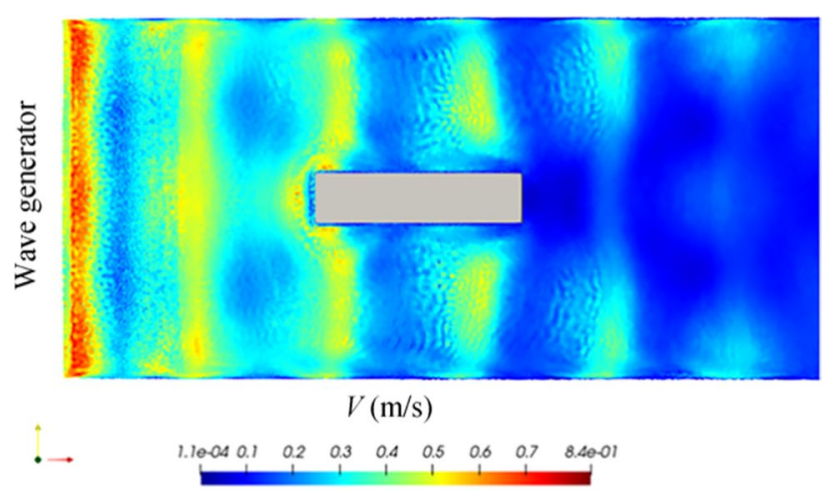

(a) $13.95 \mathrm{~s}$

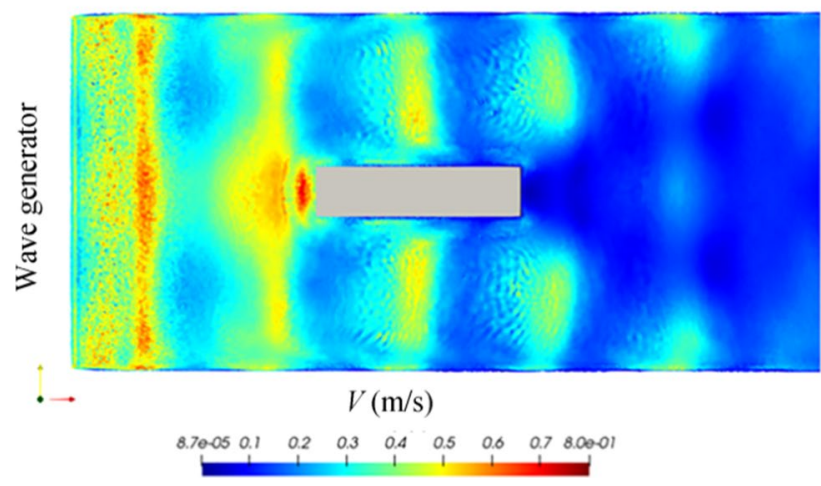

(b) $14.5 \mathrm{~s}$

Figure 11 Instantaneous wave contours around the rigid structure at $13.95 \mathrm{~s}$ and $14.5 \mathrm{~s}$ for $\omega=6.283 \mathrm{rad} / \mathrm{s}$

\section{Conclusions}

The open-source code DualSPHysics has been used as a numerical tool to study the interaction of a beveledshaped structure in head waves. This is a 3D hydrodynamic experiment to develop an efficient approach in predicting the motion response in comparison with other numerical techniques and experimental data. The beveledshaped structure was modeled using a model similar to that of Lakshmynarayanana et al. (2015), which was, in turn, based on a hydroelastic test conducted by Remy et al. (2006). Some concluding observations from the investigation are given below:

1) Overall, the motion responses of the WCSPH agreed well with the theoretical and experimental findings, except for minor disparities at low frequencies at the amidship of the structure.

2) The disparities were largely the result of the vertical motion, which was presumably affected by a strong but localized wave along the structure and a regular longcrested wave.

3) The convergence test was conducted to examine the small discrepancies noted at relatively low frequencies. However, no apparent improvement was attained through the test.

4) The overprediction of motion responses from the WCSPH occurred at bow regions, and this finding was similar to that of STAR_Rigid at relatively higher frequencies.

5) The comparison with the experimental data provided useful insights into the differences in motion responses between the rigid and deformable structures.

6) The results of this study could be improved with a hydroelastic module to simulate deformable structures. Improvements might also be achieved via a double-precision technique for particle position or variable particle resolution near the structure.

Acknowledgements The authors would also like to express our appreciation to the DualSPHysics team for their works in producing efficient solutions for engineering problems.

Funding This work was funded by the Ministry of Higher Education (MOHE) of Malaysia under the Long Term Research Grant Scheme (LRGS) No. LRGS21-001-0005 and LRGS/1/2020/UMT/01/1/4.

Open Access This article is licensed under a Creative Commons Attribution 4.0 International License, which permits use, sharing, adaptation, distribution and reproduction in any medium or format, as long as you give appropriate credit to the original author(s) and the source, provide a link to the Creative Commons licence, and indicate if changes were made. The images or other third party material in this article are included in the article's Creative Commons licence, unless indicated otherwise in a credit line to the material. If material is not included in the article's Creative Commons licence and your intended use is not permitted by statutory regulation or exceeds the permitted use, you will need to obtain permission directly from the copyright holder. To view a copy of this licence, visit http://creativecommons.org/licenses/by/4.0/.

\section{References}

Altomare C, Tafuni A, Domínguez JM, Crespo AJ, Gironella X, Sospedra J (2020) SPH simulations of real sea waves impacting a large-scale structure. Journal of Marine Science and Engineering 8(10):826. https://doi.org/10.3390/jmse8100826

Bishop RED, Price WG (1979) Hydroelasticity of ships. Cambridge University Press, Cambridge, UK, p 431

Cartwright B, Groenenboom PHL, McGuckin D (2004) Examples of ship motion and wash predictions by smoothed particle hydrodynamics (SPH). 9th Symposium on Practical Design of Ships and Other Floating Structures. Luebeck-Travemuende, Germany

Cercos-Pita JL, Bulian G, Souto-Iglesias A (2015). Time domain assessment of nonlinear coupled ship motions and sloshing in free surface tanks. Proceedings of the ASME $201534^{\text {th }}$ International 
Conference on Ocean, Offshore and Arctic Engineering, Newfoundland, Canada, 1-11

Cerello Chapchap A (2015). Unstructured MEL modelling of nonlinear $3 D$ Ship hydrodynamics. PhD thesis, University of Southampton, Southampton, 11-170

Cheng H, Ming FR, Sun PN, Sui YT, Zhang AM (2020) Ship hull slamming analysis with smoothed particle hydrodynamics method. Appl Ocean Res 101:102268. https://doi.org/10.1016/j. apor.2020.102268

Crespo AJ, Domínguez JM, Rogers BD, Gómez-Gesteira M, Longshaw S, Canelas RJFB, Vacondio R, Barreiro A, García-Feal O (2015) DualSPHysics: open-source parallel CFD solver based on smoothed particle hydrodynamics (SPH). Comput Phys Commun 187:204-216. https://doi.org/10.1016/j.cpc.2014.10.004

Domínguez JM, Fourtakas G, Altomare C, Canelas RB, Tafuni A, García-Feal O, Martínez-Estévez I, Mokos A, Vacondio R, Creapo AJC, Rogers BD, Stanby PK, Gómez-Gesteira M (2021). DualSPHysics: from fluid dynamics to multiphysics problems. Computational Particle Mechanics, 1-29. https://doi.org/10.1007/ s40571-021-00404-2

Faltinsen O, Zhao R, Umeda N (1991) Numerical predictions of ship motions at high forward speed. Philosophical Transactions of the Royal Society of London a: Mathematical, Physical and Engineering Sciences 334(1634):241-252. https://doi.org/10.1098/ rsta.1991.0011

Fonseca N, Guedes Soares C (2002) Comparison of numerical and experimental results of nonlinear wave-induced vertical ship motions and loads. J Mar Sci Technol 6(4):193-204. https://doi. org/10.1007/s007730200007

Greco M, Colicchio G, Lugni C, Faltinsen OM (2013) 3D domain decomposition for violent wave-ship interactions. Int J Numer Meth Eng 95(8):661-684. https://doi.org/10.1002/nme.4523

Huang Y, Sclavounos PD (1998) Nonlinear ship motions. J Ship Res 42(2):120-130. https://doi.org/10.5957/jsr.1998.42.2.120

Jensen JJ, Mansour AE, Olsen AS (2004) Estimation of ship motions using closed-form expressions. Ocean Eng 31(1):61-85. https:// doi.org/10.1016/S0029-8018(03)00108-2

Kawamura K, Hashimoto H, Matsuda A, Terada D (2016) SPH simulation of ship behaviour in severe water-shipping situations. Ocean Eng 120:220-229. https://doi.org/10.1016/j.oceaneng.2016.04. 026

Korvin-Kroukovsky BV, Jacobs WR (1957). Pitching and heaving motions of a ship in regular waves. Armed Services Technical Report No. AD134053. Stevens Institute of Technology Experimental Towing Tank, Hoboken, USA.

Lakshmynarayanana P, Temarel P, Chen Z (2015). Hydroelastic analysis of a flexible barge in regular waves using coupled CFD-FEM modelling. In: Guedes Soares C, Shenoi RA (Eds.). Analysis and design of marine structures: proceedings of the $5^{\text {th }}$ International Conference on Marine Structures (MARSTRUCT 2015), Southampton, 95-103

Lee ES, Violeau D, Issa R, Ploix S (2010) Application of weakly compressible and truly incompressible SPH to 3-D water collapse in waterworks. J Hydraul Res 48(sup1):50-60. https://doi.org/10. 1080/00221686.2010.9641245

Leonardi M, Domínguez JM, Rung T (2019) An approximately consistent SPH simulation approach with variable particle resolution for engineering applications. Eng Anal Boundary Elem 106:555-570. https://doi.org/10.1016/j.enganabound.2019.06.001
Liu MB, Shao JR, Li HQ (2014) An SPH model for free surface flows with moving rigid objects. Int J Numer Meth Fluids 74(9):684697. https://doi.org/10.1002/fld.3868

Lin WM, Collette M, Lavis D, Jessup S, Kuhn J (2007) Recent hydrodynamic tool development and validation for motions and slam loads on ocean-going high-speed vessels. 10th International Symposium on Practical Design of Ships and Other Floating Structures (PRADS 2007). Houston 2:1107-1116

Ma C, Oka M (2019) Numerical coupling model based on SPH and panel method to solve the sloshing effect on ship motion in wave condition. The 29th International Ocean and Polar Engineering Conference. Honolulu, USA 3:3342-3348

Monaghan JJ (1994) Simulating free surface flows with SPH. J Comput Phys 110(2):399-406. https://doi.org/10.1006/jcph.1994.1034

Monaghan JJ (2006). Time stepping algorithms for SPH. Proceedings of 1st SPHERIC Workshop, Rome, 1-6

O’Connor J, Rogers BD (2021) A fluid-structure interaction model for free-surface flows and flexible structures using smoothed particle hydrodynamics on a GPU. J Fluids Struct 104:103312. https://doi. org/10.1016/j.jfluidstructs.2021.103312

Pringgana G, Cunningham LS, Rogers BD (2021) Influence of orientation and arrangement of structures on Tsunami impact forces: numerical investigation with smoothed particle hydrodynamics. J Waterw Port Coast Ocean Eng 147(3):04021006

Ramli MZ (2018) The hydrodynamic coefficients for oscillating 2D rectangular box using weakly compressible smoothed particle hydrodynamics (WCSPH) method. IIUM Engineering Journal 19(2):172-181. https://doi.org/10.31436/iiumej.v19i2.889

Ramli MZ, Temarel P, Tan M (2018) Hydrodynamic coefficients for a 3-D uniform flexible barge using weakly compressible smoothed particle hydrodynamics. J Mar Sci Appl 17(3):330-340. https:// doi.org/10.1007/s11804-018-0044-2

Remy F, Molin B, Ledoux A (2006). Experimental and numerical study of the wave response of a flexible barge. Proceedings of the $4^{\text {th }}$ International Conference on Hydroelasticity in Marine Technology, Wuxi, 255-264

Serván-Camas B, Cercós-Pita JL, Colom-Cobb J, García-Espinosa J, Souto-Iglesias A (2016) Time domain simulation of coupled sloshing-seakeeping problems by SPH-FEM coupling. Ocean Eng 123:383-396. https://doi.org/10.1016/j.oceaneng.2016.07. 003

Sun X, Yao C, Ma C (2018) Partially nonlinear time domain analysis on ship motions in waves with translating-pulsating source Green function. Ocean Eng 170:374-391. https://doi.org/10.1016/j.ocean eng.2018.07.039

Tafuni A (2016). Smoothed particle hydrodynamics: development and application to problems of hydrodynamics. $\mathrm{PhD}$ thesis, Polytechnic Institute of New York University, New York.

Tezdogan T, Demirel YK, Kellett P, Khorasanchi M, Incecik A, Turan O (2015) Full-scale unsteady RANS CFD simulations of ship behaviour and performance in head seas due to slow steaming. Ocean Eng 97:186-206. https://doi.org/10.1016/j.oceaneng.2015. 01.011

Wendland H (1995) Computational aspects of radial basis function approximation. Elsevier

Xie X, Wan Y, Wang Q, Liu H, Feng D (2019) Numerical simulation of ship-ship interactions in waves. International Conference on Offshore Mechanics and Arctic Engineering 58776:V002T08A060. https://doi.org/10.1115/OMAE2019-95737 